\title{
Selected African American First-time Teenage Mothers' Perceptions of Nurse Caring Behaviors During the Postpartum Period
}

\author{
Danita R. Potter, Esther H. Condon, Arlene J. Montgomery, \\ Toni Sims Muhammad, and Zina T. McGee \\ Grambling State University \\ E-mail: potterd@gram.edu \\ Hampton University \\ E-mail: esther.condon@hamptonu.edu \\ Hampton University \\ E-mail: Arlene.montgomery@ hamptonu.edu \\ University of Louisiana Lafayette \\ E-mail: drtonimuhammad@gmail.com \\ Hampton University \\ E-mail: zina.mcgee@ hamptonu.edu
}

\begin{abstract}
The purpose of this study was to explore and describe African American teen mothers' perceptions of nurse caring behaviors during the postpartum period in a rural southern state. African Americans have unique cultural needs; thus, it is critical for the science of nursing to explore and describe African American teenage mothers' perceptions of nurse caring behaviors during the postpartum period. By exploring and describing African American first-time teenage mothers' perceptions of nurse caring behaviors, the researcher will help nursing science gain insight into how to facilitate and enhance postpartum care for young families. An exploratory descriptive design was used and descriptive analyses were conducted on demographic characteristics and CBA subscales to answer the research question: How do African American first-time teenage mothers describe nursing behaviors and identify the most important nursing behaviors that they received during the postpartum period? Findings indicated that there was statistical significance for the independent variable, decision
\end{abstract}


making for your health, and the Caring Behaviors Assessment (CBA) subscales of humanism/faith-hope/sensitivity ( $p=0.050)$, human needs assistance $(p=0.052)$, and the demographic characteristics. The analysis revealed attentive to needs was a common theme.

Keywords: Caring Behaviors, Perceptions, Teenage Mothers

\section{Introduction}

Teenage pregnancy rates in the United States have steadily declined over the last 10 years (Centers for Disease Control [CDC], 2004, 2008), but African American teenage pregnancy rates are three to four times higher than those of any other race or ethnic group (Guttmacher, 2006). African American families are disproportionately impacted by the consequences of early teenage childbearing (Guttmacher, 2006), and this leads to health disparities for the entire family. The literature on teenage mothers has focused on problematic issues and negative outcomes of early childbearing, and few studies have aimed to gain an understanding of the concerns of African American teenage mothers and their families (Kaplan, 1997; SmithBattle, 1997).

Moreover, research on nurse caring behaviors remains heavily focused on specific patient specialties, such as acute care (Cronin \& Harrison, 1988; Huggins, Gandy, \& Kohut, 1993; Parsons, Kee, \& Gray, 1993), long-term care (Marini, 1999), and HIV/AIDS (Mullins, 1996). There is limited research on nurse caring behaviors performed during the postpartum period, especially research related to the care of African American teenage mothers (Lomoro, Ehiri, Qian, \& Tang, 2002; Sauls, 2004; Schultz, Bridgham, Smith, \& Higgins, 1998; Winfield Manogin, Bechtel, \& Rami, 2000).

Every year in the United States over 1,000,000 births are to teenage mothers, and most of these births are to African Americans teenage mothers (Guttmacher, 2006). Negative stereotypes, blaming, and labeling of teenagers as unfit and unwed mothers have dominated the image of teenage mothers, particularly African American teenage mothers. These stereotypes have influenced the health care professional's response to providing care to African American teenage mothers (Geronimus, 1997; Kaplan, 1997; Luker, 1996; SmithBattle, 1997).

According to the National Vital Statistics System, (CDC, 2000a), major health disparities exist across ethnic groups, particularly in regard to African American teenage mothers. In 2002, African American teenage mothers were three times more likely to receive late or no prenatal care than their Caucasian counterparts. The racial divide was even greater in Louisiana (CDC, 2000b). In addition, 
African American teenage mothers felt they were often blamed for not upholding traditional American values or failing to meet moral standards and often struggled due to depleted resources of family and community and the weight of a stigma brought upon them by society, family, and friends (Kaplan, 1997; Luker, 1996; SmithBattle \& Leonard, 1998). According to Kaplan (1997), adult African American mothers of teenage mothers were overtaxed and overextended by the needs of their teenage daughters. Teenage mothers felt that teenage motherhood stigmatized not only them, but also their mothers.

This study showed that African American teenage mothers were able to discern which nurse caring behaviors were most important to them during the postpartum period. This current study explored family support, family structure, and family decision-making. Notably, first-time teenage mothers described the most important nurse caring behaviors during the postpartum period as the most common theme.

\section{Literature}

Larson (1987) found that there was a significant difference between nurses and patients in the ranking of the most important caring behaviors. Nurses perceived demonstrating comforting and trusting relationship behaviors as being most important in caring for cancer patients. On the other hand, patients perceived nursing behaviors that demonstrated being accessible, monitoring, and following through as being most caring.

Findings of Cronin and Harrison's (1988) study revealed the behaviors most indicative of caring were nursing actions that focused on providing physical care and monitoring patients. Cronin and Harrison's (1988) study identified specific caring actions of nurses and was a valuable and necessary contribution to nursing science. Results were displayed in terms of ratings of CBA items, rankings of the CBA subscales, differences in perceptions of caring, and responses to an openended question. Huggins et al. (1993) study revealed the CBA item ranked as most important caring behavior of nurses in emergency room was "know what they are doing." This item is on the human needs assistance subscale, which focuses on behaviors of technical competency of nurse care.

In Sauls's (2004) study on adolescent mothers' perceptions of nurse care during the childbirth experience, the top 10 labor support behaviors that were most helpful were as follows:

(1) praised me; (2) gave me pain medication; (3) accepted what I said and did so without judgment; (4) appeared calm and confident when giving care; (5) made me feel cared about as an individual; (6) treated me with respect; (7) attempted to 
lessen demands on me; (8) answered my questions; (9) provided distractions by talking to me; (10) assisted me in breathing/relaxing.

Lomoro et al. (2002) reported that $50 \%$ of participants stated that the services received during postpartum were not of high quality. Participants indicated that postpartum services were not long enough and there was inadequate time for them to ask questions, indicating that the nurses' time with them and their babies was too short and insufficient. First-time teenage mothers in the Lomoro et al. (2002) study indicated that nurses explaining everything to them prior to the baby coming being born, allowing time to sit and talk, and explaining everything thoroughly to her about her baby were behaviors most indicative of caring, and a similar finding was found in this study.

Winfield et al. (2000) found the human needs assistance scale $(m=4.70)$ was the highest ranked subscale while the existential/phenomenological/spiritual forces scale $(m=4.01)$ ranked as the least important scale. In this study, the human needs assistance scale $(m=4.85)$ was also ranked the highest of the seven subscales. The lowest ranked subscale was helping/trust $(m=4.29)$. Of the 10 most important perceptions of nurse caring behaviors, the top three items were "know what they're doing," "know how to handle equipment," and "give treatments and medication on time." In this study, first-time teenage mothers had very similar responses to participants in the Winfield et al. (2000) study when asked, "What did nurses do or say that was most important to you?" The responses led to the recurring theme, teaching/informative. Sample responses were "showed me how to do things I didn't know," "showed me how to do things for my baby when he cried and I was puzzled," "educate me on my life outside the hospital with a newborn," and "she taught me everything I needed to know before the baby came."

Coffman and Ray's (1999) study developed a substantive theory of support by exploring social support processes in low-income adult African American women during high-risk pregnancy and early parenthood. Results of Coffman and Ray's (1999) study revealed that poverty status, small network of kin, and unplanned pregnancy status negatively influenced pregnancy acceptance and family support. The study's findings also revealed African American mothers and their families indicated that mutual relational (primary) support and social support is not only necessary but should be present and ongoing (Coffman \& Ray, 1999).

\subsection{Theoretical Framework}

The conceptual framework consists of the Theory of Human Caring, middle range theory concepts, and empirical indicators. Figure 1 illustrates the conceptualtheoretical-empirical structure for the study of African American first-time 
teenage mothers' perceptions of nurse caring behaviors during the postpartum period. Little is known about the behaviors that communicate caring from the perspective of African American families and teenage mothers (Potter, 2005). Thus, in this research study, it was critical to explore and describe behaviors African American teenage mothers perceive as nurse caring behaviors during the postpartum period. This study can add to the body of knowledge by providing insights for nurses who care for African American first-time teenage mothers.

Caring is essential to human development, growth, and survival, and caring behavior is evident in priorities and expressions (Chinn \& Jacobs, 1987). According to Watson (1988), "Human care requires knowledge of human behavior and human processes to actual or potential health problems" (p. 74). Nurses are pivotal in communicating caring to diverse clients in private, public, and hospital settings. To be effective, caring must go beyond mere thought and intention and be communicated in action (Watson, 1979). Watson's (1985) basic assumptions state that effective caring promotes health and individual or family growth. In order for caring behaviors to be effective, the behaviors must be perceived as caring by the patient. The patient's perception of nurse caring behaviors is critical to the nurse-patient relationship (Watson, 1985).

This concept is especially important when caring for a pregnant patient because pregnancy can be a stressful experience, particularly for a first-time teenage mother. Adolescents who become pregnant require unique consideration, understanding, care, and support during their first pregnancy (American Academy of Child and Adolescent Psychiatry, 1997; Bushy, 2000). First-time teenage mothers undergo physiological, psychological, and emotional changes during their transition to motherhood (Carter \& Spear, 2002; SmithBattle, 1997; SmithBattle \& Leonard, 1998; Trad, 1995; Williams \& Vines, 1999). As a result, researchers have asserted that health care professionals must utilize an alternative view of teenage childbearing in planning their care (Geronimus, 1997; SmithBattle \& Leonard, 1998). MacLeod (2000) argues for the development of specialized knowledge and skills in the field of nursing that not only define caring as an entity but encourages such practices in the profession. To this end, caring practices should be clearly detailed with elements and practices outlined for successful implementation.

This shift in focus means that the provision of care will encompass a more holistic perspective (Koopsen and Young, 2009) - one that attends to all aspects of mind, body, and spirit.

Moreover, (Rafael 2000) Watson's theory remains relevant with contemporary approaches to community health and health promotion and identifies caring an essential component of community health nursing practice. This study was undergirded using the Watson's Theory of Human Caring consists of three major components that are middle range theory concepts. Figure 1 displays the Middle 
range theory concepts used to guide this study which were the transpersonal caring relationship, carative factors, and caring moment. The African American teenage mother-nurse transaction, important caring behaviors, postpartum period, and family support were the middle range theory subconcepts under investigation. The focus of this middle range theory was on the teenage mothers' perceptions of the nurse-client transaction.

Fig. 1: Conceptual framework for selected African American first-time teenage mother's perceptions of nurse caring behaviors during the postpartum period.

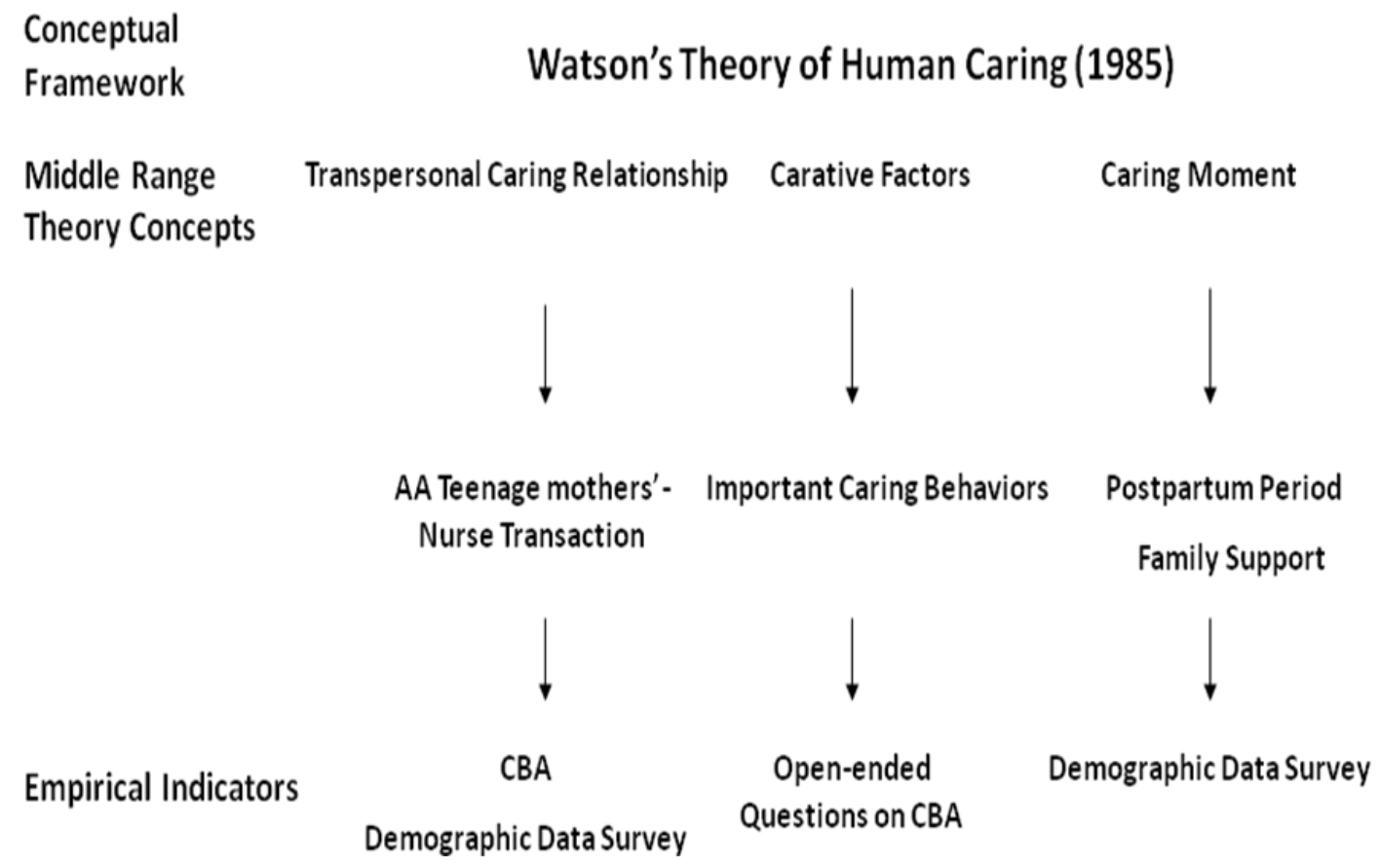

Fig. 1. Conceptual-theoretical-empirical structure (CTE) for the study of first-time African American teenage mothers' perceptions of nurse caring behaviors during postpartum.

\section{Methodology}

A descriptive design was used to answer the research questions. A 63-item, 5point Likert scale questionnaire was used to elicit responses regarding caring behaviors. Two qualitative questions were added to the CBA to answer the research questions and allow teenage mothers to describe caring in their own words. The quantitative data presented in this article were derived from a single community health facility that provided postpartum care to first-time teenage 
mothers. All participants were recruited from this location. The qualitative component of the study employed a qualitative descriptive design in order to allow participants to describe in their own words what caring behaviors are or were during the postpartum period.

\subsection{Research Questions}

The research questions guiding the study were as follows:

Research Question 1: How do African American first-time teenage mothers describe the nursing behaviors and the most important nursing behaviors that they received during the postpartum period?

$H_{l}$ : African first-time teenage mothers will discern and describe in their own words which nurse behaviors as caring and which are most important during their postpartum period.

Research Question 2: Is there a statistically significant difference between the overall CBA score, the CBA subscales ranking by mean, and previous studies using the CBA?

$\mathrm{H}_{2}$ : There will be statistically significant differences between the overall CBA score, The CBA subscale ranking by mean, and previous studies using the CBA.

Research Question 3: Are there statistically significant differences for the CBA subscales and the demographic characteristics of age, education, family income supports you, family income supports your baby, decision making for your health, decision making for your baby's health, and lives at home with you?

$H_{3}$ : There will be statistically significant differences for the CBA subscales and the demographic characteristics of African American first-time teenage mothers.

\section{Research Design}

This study used an exploratory, descriptive design to investigate African American first-time teenage mothers' perceptions of nurse caring behaviors during the postpartum period.

According to Burns and Grove (2005), "A descriptive study design is constructed to gain more information about characteristics within a particular study field and the purpose is to provide a pictorial view of a natural setting and its events" ( $p$. 232). Descriptive studies vary in design and level of complexity, and multiple variables unfold from the data. Therefore, the researcher ensures protection against bias within the descriptive design, such as definition of terms, sample selection and size, instrument validity and reliability, and data collection procedures (Burns \& Grove, 2005). In this study, the researcher used an exploratory descriptive design to answer the research questions. 
The exploratory nature of the design provided basic knowledge of this population that could be used to assess the effectiveness of Watson's Theory of Human Caring for practice with this population. The addition of two open-ended questions to the CBA provided information that may prove useful to nurses who provide care for this population.

\subsection{Sample and Setting}

A convenience sample $(N=50)$ of African American first-time teenage mothers was recruited for the study. The sample was recruited from a northeast Louisiana health care agency that provides maternal and child care services to African American first-time teenage mothers. A convenience sample was selected on the basis of availability, with no attempt at randomization. Inclusion criteria for the study were as follows: first-time mother, African American, ages $15-19$, uncomplicated delivery, received or was receiving postpartum care during the postpartum period, resided in northeast or north Louisiana, educated at the sixth grade level or higher, and demonstrated a willingness to complete a demographic data sheet and a questionnaire that identified perceptions of nurse caring behaviors.

\subsection{Instrumentation}

The CBA was administered to African American first-time teenage mothers. Cronin and Harrison (1988) designed the survey so the participant could rank an action as to its importance in providing a feeling of "being cared for and about." The researcher added two open-ended questions to the CBA to allow participants to describe their perceptions of important nurse caring behaviors in their own words.

There are 63 items with a Likert scale on the CBA, ranging from 1 to 5 , with 5 representing items of much importance and 1 representing those of little importance. This instrument has 63 nursing behaviors distributed across seven subscales congruent with Watson's carative factors. The following seven subscales are listed in order by number of subscale on the CBA. The subscales are (1) humanism/faith-hope/sensitivity; (2) helping/trust; (3) expression of positive/negative feelings; (4) teaching/learning; (5) supportive/protective/ corrective environment; (6) human needs assistance; and (7) existential/phenomenological/spiritual forces (Cronin \& Harrison, 1988).

The rationale for choosing the CBA instrument was based on the instrument's congruence with the purpose of the study, research hypotheses, and linkage with the conceptual framework selected for the study. Potter (2005) pilot tested the 
CBA for its readability and feasibility in a study conducted with first-time mothers during the postpartum period. A convenience sample of 35 participants was used and their ages ranged from $15-19$. Results of the pilot test indicated that first-time teenage mothers had no difficulties with readability, and the average time to complete the instrument was less than 15 minutes (Potter, 2005).

For this study, the researcher received permission from the developers of the instrument not to use the one open-ended question at the end of the CBA and to add two open-ended questions. A demographic data survey was used to provide characteristics of the participants and consisted of instructions for completing the survey and nine items. The demographic characteristics were age, education, marital status, previous hospitalizations, family support for you, and family support for baby, family structure, and family decision making for you, and decision making for baby. In previous studies on caring, the demographic data survey consisted of four items, which were age, education, ethnicity, and previous hospitalizations (Cronin \& Harrison, 1988; Huggins et al., 1993; Marini, 1999; Mullins, 1996).

This study sought to recruit first-time African American teenage mothers. Age was self-reported by the participants who listed their age on the demographic data survey. Participants self-reported their educational level by listing the number in years or the highest grade completed. Marital status was self-reported by participants selecting their appropriate status, and the number of prior hospitalizations was self-reported by selecting "yes" or "no" and "inpatient" or "outpatient." Family support, structure, and decision making were self-reported and/or explained. African American teenage mothers were instructed not to write their names or addresses on the demographic or CBA instruments. All demographic characteristics, CBA scores, and subscale mean scores were explored in this study to determine if there were statistically significant differences.

Data were collected during the postpartum period after hospitalization, which was up to six weeks after delivery, in the rural community health agency setting. The researcher stored the completed instruments, including demographic sheets and informed consents, in a secure, locked file until the researcher entered the data into a computer. Each demographic data survey was separated from the consent form and CBA. The researcher entered each completed questionnaire into the computer utilizing the 18.0 version of the Statistical Package for Social Sciences (SPSS). Raw data were printed and reviewed prior to being analyzed. 


\subsection{Data Analysis}

The CBA, a demographic data survey, and the two open-ended questions were used to answer the research questions. For the quantitative data, descriptive statistics of frequencies, percentages, means, and standard deviation values were used to describe the sample characteristics. With regard to the CBA subscales, Cronbach alpha reliability was calculated. Also, the data were skewed data and this violated the use of parametric inferential tests, such as the independent samples $t$-test or analysis of variance (ANOVA). The non-parametric tests of the Mann-Whitney U Test (for a two category independent variable) and the KruskalWallis Test (for a three category independent variable) were used for inferential analyses. For each of the inferential analyses, the CBA subscale was the dependent variable, and the demographic variables were the independent variables. The default level of an .05 alpha was used (Cohen, 1988).

SPSS, version 18.0, was used to analyze the quantitative data. The two openended questions were analyzed using thematic analysis. This type of qualitative analysis involves using line-by-line coding to determine themes. As outlined by Braun and Clarke (2006), all statements are independently examined and coded by two individuals. The individuals then meet to reexamine the codes and create themes, continuing to reexamine any discrepancies in their analyses until $100 \%$ agreement has been achieved.

\section{Results}

The data procedures include tables and figures in order to provide inclusive results. The respondents $(N=50)$, all of whom were first-time teenage African American teenage mothers, were conveniently recruited from a rural health agency located in northeast Louisiana that provided maternal and child care services. All participants received postpartum care during their visit to the community clinic, and the agency approved this study.

\subsection{Data Procedures}

The teenage mothers in this study ranged between 15 and 19 years of age. The mean age for participants in this study was $17.84(S D=1.15)$ years, and the median age was 18. A mean split was used to create categories, and $68 \%(n=34)$ of the sample was aged $18-19$ years. The participants were first-time African American teenage mothers, with $32 \%$ of the sample between 15 and 19 years of age, and all reported an uncomplicated healthy delivery. 
The majority of first-time mothers in this study were single, educated at the $12^{\text {th }}$ grade level, and indicated that their family's income was inadequate to support them and their baby. Data were collected from teenage mothers during the postpartum period, which ranged from one day to six weeks. Descriptive statistics for the characteristics of the sample are shown in Table 1.

Education was self-reported on the demographic data survey. Each participant was able to read and write English at a seventh-grade level or higher. Educational levels ranged from the eighth to the $12^{\text {th }}$ grade. The mean educational level was 11.14 years $(\mathrm{SD}=1.20)$. A mean split was used to create categories, and $56 \%(n=$ 28 ) of the teenage mothers indicated that they were educated at the $12^{\text {th }}$ grade level.

No inferential statistics were used to analyze the marital status of the sample. This occurred because almost all participants selected "not married" on the demographic data survey. This included 48 participants $(96.0 \%)$ who selected "single" and two participants $(4.0 \%)$ who selected "married or living with partner."

Family support was self-reported on the demographic data survey. All participants responded to this question. Seven participants indicated that their family income was adequate to support them, while 43 participants indicated that their family income was not adequate.

There was a $100 \%$ response rate for family support for the baby. Forty-four ( $n=$ 44) participants indicated that the level of family support they received for the baby was not adequate. Six $(n=6)$ participants indicated that their family's income was adequate to support the baby.

Participants self-reported health decision making for you at a $100 \%$ response rate. There were three categories. The categories were "you" $(n=28)$, "you and your partner" $(n=4)$, and "you, parents/others" $(n=18)$.

Participants had a $100 \%$ response rate when asked about health decision making for baby. The participants had a selection of three possible responses. There were in three categories: "you" $(n=22)$, "you and partner" $(n=10)$, and "you, parents/others" $(n=18)$.

Participants had a $100 \%$ response rate for family structure. There were three possible responses to this question. Categories were "lives at home with you" ( $n=$ $10)$, "lives with you, baby, and partner" $(n=10)$, and "lives with you, baby, parents/others"

$(n=20)$. 
Table 1: Descriptive Statistics of the Sample

\begin{tabular}{|c|c|c|}
\hline Variable & Percentage & Frequency \\
\hline $\begin{array}{l}\text { Age (years) } \\
15-17 \\
18-19\end{array}$ & $\begin{array}{l}32.0 \% \\
68.0 \%\end{array}$ & $\begin{array}{l}(n=16) \\
(n=34)\end{array}$ \\
\hline $\begin{array}{c}\text { Education } \\
8-11 \\
12 \\
\end{array}$ & $\begin{array}{l}44.0 \% \\
56.0 \% \\
\end{array}$ & $\begin{array}{l}(n=22) \\
(n=28)\end{array}$ \\
\hline $\begin{array}{l}\text { Family Income Support Your Baby } \\
\text { Yes } \\
\text { No }\end{array}$ & $\begin{array}{l}12.0 \% \\
88.0 \%\end{array}$ & $\begin{array}{c}(n=6) \\
(n=44)\end{array}$ \\
\hline $\begin{array}{l}\text { Family Income Support You } \\
\text { Yes } \\
\text { No }\end{array}$ & $\begin{array}{l}14.0 \% \\
43.0 \% \\
\end{array}$ & $\begin{array}{c}(n=7) \\
(n=43)\end{array}$ \\
\hline $\begin{array}{l}\text { Decision Making for Baby's Health } \\
\text { You } \\
\text { You and partner } \\
\text { You, parents/others }\end{array}$ & $\begin{array}{l}44.0 \% \\
20.0 \% \\
36.0 \% \\
\end{array}$ & $\begin{array}{l}(n=22) \\
(n=10) \\
(n=18)\end{array}$ \\
\hline $\begin{array}{l}\text { Decision Making for Your Health } \\
\text { You } \\
\text { You and partner } \\
\text { You, parents/others }\end{array}$ & $\begin{array}{r}56.0 \% \\
8.0 \% \\
36.0 \%\end{array}$ & $\begin{array}{l}(n=28) \\
(n=4) \\
(n=18)\end{array}$ \\
\hline $\begin{array}{l}\text { Lives at Home with You } \\
\text { You } \\
\text { You, baby, and partner } \\
\text { You, baby, partner, parents, siblings }\end{array}$ & $\begin{array}{l}20.0 \% \\
20.0 \% \\
60.0 \%\end{array}$ & $\begin{array}{l}(n=10) \\
(n=10) \\
(n=30)\end{array}$ \\
\hline
\end{tabular}

\subsection{Discussion of Findings}

The findings demonstrated that African American first-time teenage mothers believed that nurse caring behaviors were important. The overall CBA score was calculated by summing all items of the seven subscale scores and dividing them by 7. The overall score for the CBA instrument was 4.62.

The mean scores were used to rank the seven subscales of the CBA. Data analysis indicated that African American first-time teenage mothers' perceived subscale 6, human needs assistance, as the most important subscale on the CBA. The means were ranked according to the order of importance (highest to lowest) from descriptive analysis: (1) human needs assistance (4.85); (2) humanism/faith- 
hope/sensitivity (4.77), (3) supportive/protective/corrective environment (4.69), (4) teaching/learning (4.67), (5) existential/phenomenological/spiritual forces (4.58), (6) expression of positive/ negative feelings (4.54), and (7) helping/trust (4.30). A summary of the results of the CBA subscale rankings by mean is displayed in Table 2 .

Table 2: Ranking of CBA Subscales by Mean

\begin{tabular}{|c|c|c|}
\hline Subscale & Mean & Rank \\
\hline Human needs assistance & 4.85 & 1 \\
\hline Humanism/faith-hope/sensitivity & 4.77 & 2 \\
\hline Supportive/protective/corrective environment & 4.69 & 3 \\
\hline Teaching/learning & 4.67 & 4 \\
\hline Existential/phenomenological/spiritual forces & 4.58 & 5 \\
\hline Expression of positive/negative feelings & 4.54 & 6 \\
\hline Helping/trust & 4.30 & 7 \\
\hline Overall CBA Score & 4.62 & \\
\hline
\end{tabular}

Comparisons of Demographic Data to the Subscales of the CBA

Comparisons were made between each independent variables, age, education, family income support you, family income support baby, health decision making for baby, health decision making for you, lives you and the dependent CBA subscales. When comparisons were made between both groups of teenage mothers on the variables of "age" to the CBA subscales, "family income supports you", and "family income support baby", there was no statistical significance found for any of the CBA subscales.

When comparisons of the independent variable of education with the CBA subscales were made only the CBA subscale of "Expression of positive/negative feelings" had statistical significance, and participants with 12 years of education had greater mean scores than those with between 8 and 11 years of education. All the other comparisons did not have statistical significance.

The comparisons of the independent variable of "decision making for your health" to the CBA subscales revealed that "Supportive/protective/corrective environment" was statistically significant with greater mean values for "your parents/others" as compared to "you alone." All the other comparisons did not have statistical significance.

The comparisons of the independent variable of "decision making for your baby's health" to the CBA subscales revealed that two variables that approached significance. "Humanism/faith-hope/sensitivity" had a $p$ value of 0.050 , and "your parents/others" had the highest mean, followed by "you alone." The lowest mean was "you and your partner." Also, "Human needs assistance" had a $p$ value 
of 0.052 . The same pattern occurred with "your parents/others," which had the highest mean, followed by "you alone" and "you and your partner," which had the lowest mean.

Table 3 displays themes for the open-ended question, "What did nurses do or say that made you feel cared for?" This table displays the theme categories, number of individual responses, and number of themes. The most common theme was attentive to needs. A sample response is "They always talked and check on me to see how I was doing." Another theme was reassurance/restoring hope, and a sample response is "Just relax; everything will be okay. Just believe and you'll do just fine." Another theme was a complimentary/positive attitude. A sample response is "And how are you doing? He's cute." Eight individuals did not respond to this question. One individual did not feel nurses were caring and stated, "They never really make me feel like I'm cared for."

Table 3: What Did Nurses Do or Say That Made You Feel Cared For? What Did Nurses Do or Say That Made You Feel Cared For?

\begin{tabular}{ccc}
\hline Name of Theme/ & Number of Thematic & Examples of Verbatim \\
Category & Responses $(n=42)$ & Responses \\
\hline
\end{tabular}

Attentive to needs

27

Reassurance/restoring hope

9

Complimentary/positive attitude 5
"They always talked and check on me to see how I was doing"

"Held on conversations and tried to get to know me"

"Keep checking to make sure the baby and I were okay"

"Just relax; everything will be okay. Just believe and you'll do just fine"

"She always told me that everything will always be ok, first keep trying"

“They made me feel like I'm family and at my own home"

"All my nurses had great attitudes" 
Table 4 displays the themes for the open-ended question, "What did nurses do or say that was most important to you?" There were four themes. The most common theme was attentive to needs. A sample response was "Ask if I was okay or need anything all the time." Another theme was reassurance/restoring hope, and a sample response was "Helping me when I got frustrated with trying to care for my newborn baby." Teaching/ informative was another theme. A sample response was "Help me learn about my baby so I can do it myself." Another theme was complimentary positive attitude. A sample response was "They told me that my baby was very pretty." Also, 11 individuals did not respond to this question and one responded with a statement that reflected a perception of noncaring on the part of the nurse: "Most nurses don't care about teenage moms and think just because we got pregnant at a young age that we are not considered a real parent; nurses never say or do stuff to make me feel better."

Table 4: What Did Nurses Do or Say That Was Most Important to You?

\begin{tabular}{llc}
\hline $\begin{array}{l}\text { Name of Theme } \\
\text { Category }\end{array}$ & Number of Thematic & Examples of Verbatim \\
Responses $(n=42)$ & Responses \\
\hline
\end{tabular}

Attentive to needs

Reassurance/restoring

hope

Teaching/informative
4

4
"Made sure I was comfortable and explained every procedure to me thoroughly"

"Helping when I got frustrated with trying to care for my new born"

"Showed me how to do things I didn't know"

"Showed me how to do things for my baby when he cried and I was puzzled"

When participants were asked, "Do you feel that your family's income supports you?" most participants (86\%) indicated that their family income did not support them. This may suggest that first-time teenage mothers rely heavily on supportive programs to assist with their financial needs and that their families may also need additional support. First-time teenage mothers may require additional opportunities to describe what family support means to them and their family. 
The majority of participants $(88 \%)$ responded that their family income was not adequate to support the baby when asked, "Do you feel that your family's income supports your baby?" This may suggest that for first-time teenage mothers in this study the thought of family supporting their baby meant that the family would provide additional money, items, assistance with travel, day care, or child care assistance.

The overall CBA score revealed that first-time teen mothers rated nurse caring behaviors as important, and the CBA mean score was 4.62 . This suggests that both groups of teenage mothers, the younger and older group, not only perceived things that nurses said or did as caring, but also indicated how important nurse caring behaviors were to them during the postpartum period. Non-parametric analysis, through the Mann-Whitney $\mathrm{U}$ Test, revealed that the CBA subscale mean scores indicated a $p$ value of 0.05 was found to be significant. The human needs assistance subscale was ranked as the most important scale, and the helping/trust subscale was ranked as least important.

Participants' answers to the two open-ended questions revealed that for African American teen mothers the most important nurse caring behaviors were "respect me when I was moody or cranky"; "they always talked and checked on me to see how I was doing"; and "kept checking to make sure the baby and I were okay." These findings were significantly related to the conceptual theoretical framework and previous qualitative studies. Almost all of the participants $(N=48,96 \%)$ answered the two open-ended questions. A significant descriptive finding that differed from items on the CBA was a response to the first open-ended question, "What did nurses do or say that made you feel cared for and about?" The response was "They made me feel like I'm family and at my own home." The CBA does not include this item.

African American teenage mothers were asked, "Who makes decisions for your health and for your baby's health?" Fifty-six percent indicated that they make their own decisions about their health, and 44\% indicated they make decisions regarding their baby's health. Although the majority of the teenage mothers indicated they were single, many indicated that they and their baby resided with family members or others. This finding suggests that there is a difference in how autonomy is expressed and perceived regarding health decisions. It also suggests that teenage mothers are aware of their rights to make their own health decisions. There were two statements that were consistent with Riemen's (1986) study on caring and non-caring. Two statements given in response to the open-ended questions were "They never really make me feel like I'm cared for" and "Most nurses don't care about teenage moms and think just because we got pregnant at a young age that we are not considered a real parent; nurses never say or do stuff to make me feel better." These responses suggest that non-caring behaviors may need to be assessed, analyzed, and/or explored among teenage mothers and may 
reflect why many teenage mothers do not seek care or stay adherent to their plan of care.

An important findings of the present study indicated that first-time teenage mothers perceived nurse caring behaviors as important during the postpartum period. Data analysis revealed an overall CBA score of 4.62. This finding may suggest that first-time teen mothers felt that nurse caring behaviors were important during the postpartum period or that postpartum nurses provided care that was reflected as important to them.

The findings suggest that nurse behaviors that involved attending to physical conditions and demonstrating competency were viewed as caring by participants of this study. This suggests that in these studies participants' perceived technical nursing skills as important indicators of nurse caring.

Another finding of this study rated the least important nurse caring behaviors. The helping/trust subscale consists of items, such as "really listen to me when I talk," "talk to me about my life outside the hospital," and "ask me what I like to be called." This may suggest that first-time mothers may feel that a nurse's interpersonal competency was not as important as a nurse's technical skills. However, given the transition to new mother role and the postpartum period, it is critical that nurses are aware of the benefits of a helping/trust relationship. Given the timing and situation of new mother role, it was not surprising that participants valued competent care and close attention by the nurse. The awareness of the development of a caring relationship can enhance nursing care.

The non-parametric Mann-Whitney U Test revealed five significant associations between the CBA subscale scores and demographic variables. The CBA of 4.62 suggests that nurse caring behaviors are important to first-time African American teenage mothers during the postpartum period. It is also suggested that these nurse caring behaviors be implemented by the nurses of these teenage mothers. The overall CBA high mean score suggests that first-time young mothers are really attuned to what nurses are saying and doing during this critical transition period.

Data analysis also revealed that African American teen mothers in this study indicated that "things that nurses do or say" were most important to them and were reoccurring themes in the attentive to needs categories. African American teen mothers also felt that "things that nurses did or said that made them feel cared for and about" were reoccurring themes of attentive to needs $(n=27)$, reassurance/restoring hope $(n=9)$, and complimentary/positive attitude $(n=5)$. In this study thematic analysis was used and revealed that the most common theme to question 1 and 2 was attentive to needs. 


\section{Conclusion}

This study found unique descriptors of important nurse caring during the postpartum period as described by African American first-time mothers, and demonstrate how nurse caring behaviors are perceived and described. Nurse caring behaviors are perceived as being important by first-time mothers. Therefore, the postpartum period is a critical time to listen, offer self, instill hope, and care for the teenage mother with a non-judgmental attitude.

First-time mothers perceived the technical competency of the postpartum nurse to be of greatest importance and viewed competent nurses as caring. By knowing preferred caring behaviors of the African American first-time teenage mother, postpartum nurses and other health care professionals can provide care that is culturally appropriate while enhancing the mothers' growth and development.

\section{Acknowledgements}

This research was partially funded by the Johnson \& Johnson Campaign for Nursing's Future-American Association of Colleges of Nursing Minority Nurse Faculty Scholarship. A special thanks to Solecare Health Center.

\section{References}

[1] American Academy of Child and Adolescent Psychiatry. (1997). When children have children. Retrieved from http://www.aacp.org/publication/factsfam/pregnant.htm

[2] Braun, V., \& Clarke, V. (2006). Using thematic analysis in psychology. Qualitative Research in Psychology, 3, 77-101.

[3] Burns, S., \& Grove, S. K. (2005). The practice of nursing research: Conduct, critique, and utilization (5th ed.). St. Louis, MO: Elsevier Saunders.

[4] Bushy, A. (2000). Orientation to nursing in the rural community. Thousand Oaks, CA: Sage.

[5] Carter, K., F., \& Spear, H. J. (2002). Knowledge, attitudes, and behavior related to pregnancy in a rural teenage population. Journal of Community Health Nursing, 19(2), 65-75.

[6] Centers for Disease Control and Prevention (2000a). National and state specific pregnancy rates among adolescents-United States, 1995-1997 [Electronic version]. Mortality and Morbidity Weekly Report, 49(27), 605- 
611. Retrieved from http://www.cdc.gov/mmwr/preview/ mmwrhtml/mm4927a1.htm

[7] Centers for Disease Control and Prevention. (2000b). National vital statistics reports. Infant mortality statistics from the 1998 period linked birth/infant death data set. from http://www.cdc.gov/nchs/data/nvsr/nvsr48/nvs48_12.pdf

[8] Centers for Disease Control and Prevention. (2004). Entry into prenatal care: United States 1989-1997 [Electronic version]. Morbidity and Mortality Weekly Report, 49(18), 393-397. Retrieved from http://www.cdc.gov/nchs/data/nvsr/nvsr52/nvsr52_23.pdf

[9] Centers for Disease Control and Prevention. (2008). National center for health statistics data on teenage pregnancy. Retrieved from http://www.cdc.gov/nchs/data/ infosheets/infosheet_teen_preg.pdf

[10] Chinn, P. L., \& Jacobs, M. K. (1987). Theory and nursing (2nd ed.). St. Louis, MO: Mosby.

[11] Coffman, S., \& Ray, M. A. (1999). Mutual intentionality: A theory of support processes in pregnant African American women. Qualitative Health Research, 9(4), 479-492.

[12] Cohen, J. (1988). Statistical power analysis for the behavioral sciences (2nd ed.). Hillsdale, NJ: Erlbaum.

[13] Cronin, S. N., \& Harrison, B. (1988). Psychological aspects of care. Importance of nurse caring behaviors as perceived by patients after myocardial infarction. Heart and Lung, 17(4), 374-380.

[14] Falk, R., \& Adeline, R. (2000). Watson's Philosophy, Science, and Theory of Human Caring as a Conceptual Framework for Guiding Community Health Nursing Practice. Advances in Nursing Science, 23(2), 34-49.

[15] Geronimus, A. T. (1997). Teenage childbearing and personal responsibility: An alternative view. Political Science Quarterly, 112, 405-430.

[16] Guttmacher, A. F. (2006). U. S. teenage pregnancy statistics national and state trends and trends by race and ethnicity. Retrieved from http://www.guttmacher.org/ pubs/2006/09/12/USTPstats.pdf

[17] Huggins, K. N., Gandy, W. M., \& Kohut, C. D. (1993). Emergency department patient's perception of nurse caring behaviors. Heart and Lung, 22(4), 356-364.

[18] Kaplan, E. B. (1997). Not our kind of girl: Unraveling the myths of Black teenage motherhood. Berkeley, CA: University of California, Berkeley. 
[19] Koopsen, C. \& Young, C. (2009). Integrative health holistic approach for healthcare professionals. Massachusetts: Jones and Bartlett.

[20] Larson, P. J. (1987). Comparison of cancer patients' and professional nurses' perceptions of important nurse caring behaviors. Heart and Lung, 16(2), 187193.

[21] Lomoro, O. A., Ehiri, J. E., Qian, X., \& Tang, S. L. (2002). Mothers' perspectives on the quality of postpartum care in Central Shanghai, China. International Journal for Quality on Health Care, 14(5), 393-402.

[22] Luker, K. (1996). Dubious conceptions: The politics of teenage pregnancy (pp. 1-193). Cambridge, MA: Harvard University Press.

[23] MacLeod, R. (2000). Learning to care: a medical perspective Palliative Medicine, 14(3), 209-216.

[24] Marini, B. (1999). Institutionalized older adults' perceptions of nurse caring behaviors: A pilot study. Journal of Gerontology Nursing, 25(5), 10-16.

[25] Mullins, I. L. (1996). Nurse caring behaviors for persons with acquired immunodeficiency syndrome/human immunodeficiency virus. Applied Nursing Research, 9(1), 18-23.

[26] Parsons, E. C., Kee, C. C., \& Gray, D. P. (1993). Perioperative nurse caring behaviors: Perceptions of surgical patients. AORN, 57, 1106-1114.

[27] Potter, D. (2005). First-time teenage mothers' perceptions of nurse caring behaviors. Unpublished master's thesis, Alcorn State University, Lorman, Mississippi.

[28] Sauls, D. J. (2004). Adolescents' perceptions of support during labor. The Journal of Perinatal Education, 13(4), 36-42.

[29] Schultz, A. A., Bridgham, C., Smith, M. E., \& Higgins, D. (1998). Perceptions of caring: Comparison of antepartum and postpartum patients. Clinical Nursing Research, 7(4), 369-378.

[30] SmithBattle, L. (1997). Change and continuity in family care giving practices with young mothers and their children. Image: Journal of Nursing Scholarship, 29(2), 145-150.

[31] SmithBattle, L., \& Leonard, V. W. (1998). Adolescent mothers four years later: Narratives of the self and visions of the future. Advances in Nursing Science, 20(3), 36-49.

[32] Trad, P. V. (1995). Mental health of adolescent mothers. Journal of the American Academy of Child \& Adolescent Psychiatry, 34, 130-142.

[33] Watson, J. (1979). Nursing: The philosophy and science of caring. Boston, MA: Little, Brown \& Company.

[34] Watson, J. (1985). Nursing: The philosophy and science of caring. Boulder, CO: Colorado Associated University Press.

[35] Watson, J. (1988). Nursing: Human science and human care. New York, NY: National League for Nursing. 
[36] Watson, J. (2001). Theory of human caring. In M. E. Parker (Ed.), Nursing theories and nursing practice (pp. 343-354). Philadelphia, PA: F. A. Davis.

[37] Williams, C., \& Vines, S. W. (1999). Broken past, fragile future: Personal stories of high-risk adolescent mothers. Journal of the Society of Pediatric Nurses, 4(1), 15-23.

[38] Winfield M.T., Bechtel, G. A., \& Rami, J. S. (2000). Caring behaviors by nurses: Women's perceptions during childbirth. Journal of Obstetric, Gynecologic, \& Neonatal Nursing, 29(2), 153-157. 